\title{
Development of Giant Magnetoresistance Material Based on Cobalt Ferrite
}

\author{
M. Djamal ${ }^{a, b, *}$, RAMli $^{c}$, Khairurrijal $^{a}$ And F. HARYANTO $^{a}$ \\ ${ }^{a}$ Institut Teknologi Bandung, Department of Physics, Jl. Ganesa 10, Bandung, Indonesia \\ ${ }^{b}$ Institut Teknologi Sumatera, Department of Physics, Jl. Terusan Ryacudu, Lampung Selatan, Indonesia \\ ${ }^{c}$ Universitas Negeri Padang, Department of Physics, Jl. Prof. Hamka, Padang, Indonesia
}

\begin{abstract}
This paper describes an experimental study on development of giant magnetoresistance material based on cobalt ferrite $\left(\mathrm{CoFe}_{2} \mathrm{O}_{4}\right)$. We have successfully developed a new giant magnetoresistance material based on $\mathrm{CoFe}_{2} \mathrm{O}_{4}$ i.e; sandwich $\left(\mathrm{CoFe}_{2} \mathrm{O}_{4} / \mathrm{CuO} / \mathrm{CoFe}_{2} \mathrm{O}_{4}\right)$, spin valve $\left(\mathrm{FeMn} / \mathrm{CoFe}_{2} \mathrm{O}_{4} / \mathrm{CuO} / \mathrm{CoFe}_{2} \mathrm{O}_{4}\right)$, and organic giant magnetoresistance $\left(\mathrm{CoFe}_{2} \mathrm{O}_{4} / \mathrm{Alq}_{3} / \mathrm{CoFe}_{2} \mathrm{O}_{4}\right)$ using dc-opposed target magnetron sputtering method. Crystalline structure and morphology of thin films were characterized by X-ray diffraction and scanning electron microscope. The electrical properties were characterized using a four-point probe and magnetic properties were characterized using a vibrating sample magnetometer. In sandwich structure, the giant magnetoresistance ratio maximum are found at room temperature in $\mathrm{CoFe}_{2} \mathrm{O}_{4} / \mathrm{CuO} / \mathrm{CoFe}_{2} \mathrm{O}_{4}$ thin film is $70 \%$ when $\mathrm{CoFe}_{2} \mathrm{O}_{4}$ and $\mathrm{CuO}$ layer thickness are $62.5 \mathrm{~nm}$ and $14.4 \mathrm{~nm}$, respectively. The maximum of giant magnetoresistance ratio of the spin valve structure obtained is $32.5 \%$ at FeMn layer thickness of $45 \mathrm{~nm}$. Meanwhile, in organic giant magnetoresistance the maximum value of the giant magnetoresistance ratio are approximately $35.5 \%$ at room temperature.
\end{abstract}

DOI: 10.12693/APhysPolA.128.B-19

PACS: 75.47.De, 81.15.Cd

\section{Introduction}

The giant magnetoresistance (GMR) material promises some important applications, which has many attractive features, for example: low price as compared to other magnetic sensors, its electric and magnetic properties can be varied in very wide range, low-power consumption, and reduction size [1]. Until now, the GMR material is still experience the process of research and development by the researcher. These materials are; metal [1], alloy [2, 3], semiconductors [4], organic semiconductors [5] and magnetic oxide [6, 7].

Ferrite is one of the candidates of the magnetic oxide that could potentially be used as a constituent layer GMR [8, 9]. Ferrite is ferrimagnetic oxide with a Curie temperature above room temperature. Below the Curie temperature, as well as ferromagnetic materials, ferrimagetic exhibit the same behavior that the presence of spontaneous magnetization at room temperature because it has a total magnetic moment is not zero, has a saturated magnetic domain and shows the hysteresis phenomenon [10].

One of the family ferrite used in this study were of cobalt ferrite $\left(\mathrm{CoFe}_{2} \mathrm{O}_{4}\right)$ which has the Curie temperature $520^{\circ} \mathrm{C}[10]$. Moreover, the $\mathrm{CoFe}_{2} \mathrm{O}_{4}$ has several advantages that have Curie temperature and saturation magnetization relative high, good chemical stability [11], easily prepared and relative cheap. Recently, the $\mathrm{CoFe}_{2} \mathrm{O}_{4}$ has been used in spintronic devices as a layer

*corresponding author; e-mail: mitra@fi.itb.ac.id in the spin valve [8] and spin filter [9]. In this paper, we report the development of GMR material based on $\mathrm{CoFe}_{2} \mathrm{O}_{4}$ with three structures i.e. sandwich, spin valve, and organic GMR using dc-opposed target magnetron sputtering method.

\section{Experimental}

The GMR thin films were prepared by opposed target magnetron sputtering onto silicon substrate. The deposition parameters are; time of growth was varied (corresponding to GMR thickness), flow rate of Argon gas of $100 \mathrm{sccm}$, deposition pressure of 0.54 Torr, plasma voltage of $600 \mathrm{~V}$ and growth temperature of $100^{\circ} \mathrm{C}$. The crystalline structure and morphology of thin films were characterized by X-ray diffraction (XRD) and scanning electron microscope (SEM). The magnetoresistance (MR) ratio of films was investigated using four point methods with current perpendicular plane. All measurements were conducted in room temperature.

\section{Result and discussion}

An experimental study on development of GMR materials based on cobalt ferrite using dc-OTMS method will describe in this section. The GMR thin films have been develop with three structures, i.e. the $\mathrm{CoFe}_{2} \mathrm{O}_{4} / \mathrm{CuO} / \mathrm{CoFe}_{2} \mathrm{O}_{4}$ sandwich, $\mathrm{CoFe}_{2} \mathrm{O}_{4} / \mathrm{CuO} / \mathrm{CoFe}_{2} \mathrm{O}_{4} / \mathrm{FeMn}$ spin valve and GMR organic $\mathrm{CoFe}_{2} \mathrm{O}_{4} / \mathrm{Alq}_{3} / \mathrm{CoFe}_{2} \mathrm{O}_{4}$. 


\subsection{The $\left(\mathrm{CoFe}_{2} \mathrm{O}_{4} / \mathrm{CuO} / \mathrm{CoFe}_{2} \mathrm{O}_{4}\right)$ sandwich}

The $\mathrm{CoFe}_{2} \mathrm{O}_{4} / \mathrm{CuO} / \mathrm{CoFe}_{2} \mathrm{O}_{4}$ sandwich has been grown on $\mathrm{Si}$ (111) substrates. It is known from the results of characterization by XRD. Figure 1 shows XRD pattern of $\mathrm{CoFe}_{2} \mathrm{O}_{4} / \mathrm{CuO} / \mathrm{CoFe}_{2} \mathrm{O}_{4}$ sandwich for different $\mathrm{CoFe}_{2} \mathrm{O}_{4}$ layer thickness.

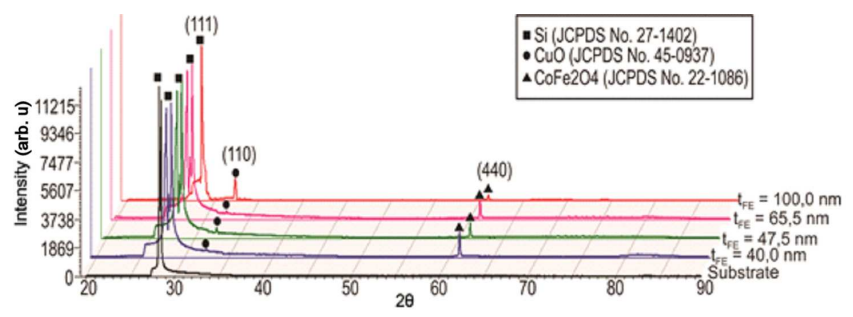

Fig. 1. The diffraction pattern of $\mathrm{CoFe}_{2} \mathrm{O}_{4} / \mathrm{CuO} / \mathrm{CoFe}_{2} \mathrm{O}_{4}$ with varied $\mathrm{CoFe}_{2} \mathrm{O}_{4}$ layer thickness and fixed $\mathrm{CuO}$ layer thickness $(14.4 \mathrm{~nm})$. $\mathrm{X}$-ray wave length is $\lambda=1.54056 \AA$.

As shown in Fig. 1, the sandwich GMR $\mathrm{CoFe}_{2} \mathrm{O}_{4} / \mathrm{CuO} / \mathrm{CoFe}_{2} \mathrm{O}_{4}$ which had been grown, where the crystal diffraction peaks that appear are $\mathrm{Si}$ (111) at an angle of $2 \theta=28.4^{\circ}$ (JCPDS No. 27-1402), $\mathrm{CuO}(110)$ at an angle of $2 \theta=32.4^{\circ}$ (JCPDS No. 45-0937), and $\mathrm{CoFe}_{2} \mathrm{O}_{4}$ (440) at an angle of $2 \theta=62.5^{\circ}$ (JCPDS No. 22-1086).

One of the microstructure parameters were analyzed in this study is the size of crystallites. Crystallite size can be estimated by using the Scherrer formula in Eq. (1) [12].

$$
d=\frac{K \lambda}{\beta \cos \theta},
$$

where $d$ is the grain size, $\lambda$ is the wavelength of $\mathrm{X}$ ray, $\beta$ is the FWHM (full width at half maximum) of the diffraction peak ( $\beta$ expressed in radians), $\theta$ is the Bragg diffraction angle, and $K$ is the Scherrer constant. Based on the results of the calculation of crystallite size and measurement GMR ratio for the sandwich of $\mathrm{CoFe}_{2} \mathrm{O}_{4} / \mathrm{CuO} / \mathrm{CoFe}_{2} \mathrm{O}_{4}$ can be studied the effect of crystallite size on the GMR ratio as shown in Fig. 2.

In this figure, the maximum GMR ratio is obtained when the small grain size. This value occurs for $\mathrm{CoFe}_{2} \mathrm{O}_{4}$ sandwich with a thick layer of $44.4 \mathrm{~nm}$ which has a maximum GMR ratio with a value of $70 \%$. In theory particles with small size indicate the surface to volume ratio is greater, so it has a relatively large contribution to the GMR effect [13]. It is related to the scattering at the surface is larger when a small particle size. As is known, that the magnetoresistance associated with spin dependent scattering and, thus GMR ratio becomes larger when the scattering is larger.

\subsubsection{Effect of $\mathrm{CuO}$ layer thickness}

In the experiments, the parameters are varied thickness of $\mathrm{CuO}$, while $\mathrm{CoFe}_{2} \mathrm{O}_{4}$ thickness fixed at $62.5 \mathrm{~nm}$. The GMR ratio of $\mathrm{CoFe}_{2} \mathrm{O}_{4} / \mathrm{CuO} / \mathrm{CoFe}_{2} \mathrm{O}_{4}$ as a function of $\mathrm{CuO}$ layer thickness is shown in Fig. 3. In this study, it was found the negative value of magnetoresistance ratio,

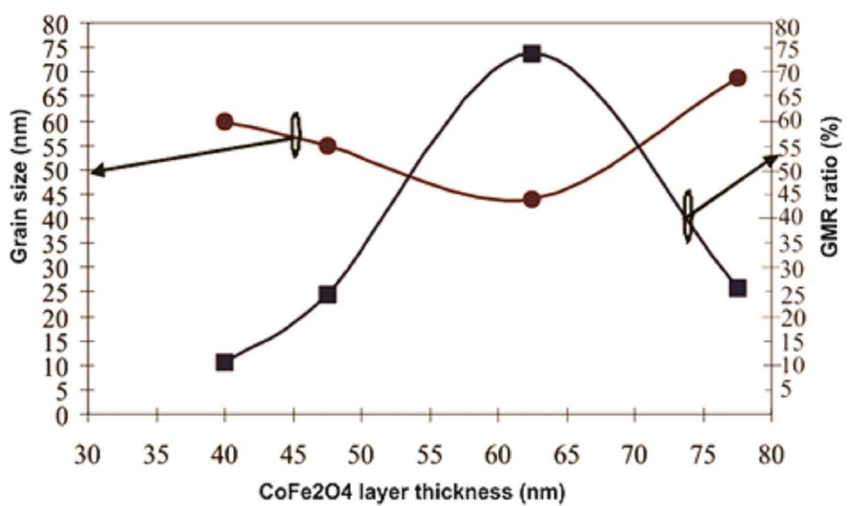

Fig. 2. $\mathrm{CoFe}_{2} \mathrm{O}_{4}$ layer thickness variation against grain size and the ratio GMR of the sandwich GMR $\mathrm{CoFe}_{2} \mathrm{O}_{4} / \mathrm{CuO} / \mathrm{CoFe}_{2} \mathrm{O}_{4}$ for $\mathrm{CuO}$ layer thickness of $14.4 \mathrm{~nm}$.

which means the resistance of the material decrease with increasing of applied magnetic field.

Figure 3 shows the GMR ratio decreases with increasing of the $\mathrm{CuO}$ layer thickness. When the $\mathrm{CuO}$ layer thickness increases, the conductivity through the GMR layer becomes very dominant and spin-dependent scattering is not effective, so the GMR ratio is reduced.

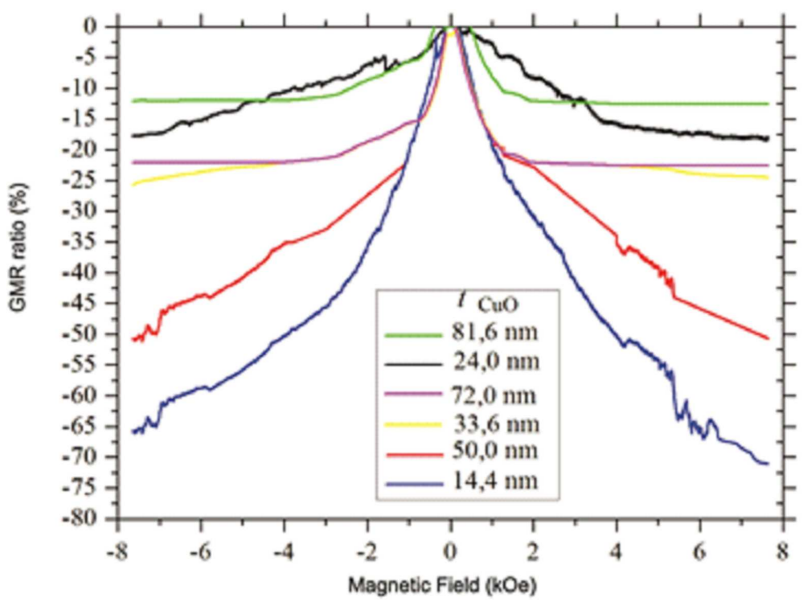

Fig. 3. The GMR ratio curves of $\mathrm{CoFe}_{2} \mathrm{O}_{4} / \mathrm{CuO} / \mathrm{CoFe}_{2} \mathrm{O}_{4}$ with different $\mathrm{CuO}$ layer thickness at fixed $\mathrm{CoFe}_{2} \mathrm{O}_{4}$ layer thickness $62.5 \mathrm{~nm}$.

To explain the above mentioned experimental findings, we propose an indirect exchange coupling model, which was well known in a layered system containing two ferromagnetic layers and a nonmagnetic spacer relate to the oscillatory interlayer coupling [14].

Energy per unit area of the interlayer exchange coupling is expressed by Eq. (2) [15].

$$
W_{1}=-J_{1} \frac{\boldsymbol{M}_{1} \cdot \boldsymbol{M}_{2}}{\left|\boldsymbol{M}_{1}\right|\left|\boldsymbol{M}_{2}\right|}=-J_{1} \cos \Delta \varphi,
$$

where $\boldsymbol{M}_{1}, \boldsymbol{M}_{2}$ is magnetization in each ferromagnetic (FM) layer, $\Delta \varphi$ is angle between $\boldsymbol{M}_{1}$ and $\boldsymbol{M}_{2}$ and $J_{1}$ is 
coupling constant. The positive value of the coupling coefficient $J_{1}$ means that the coupling is FM coupling, while negative values of $J_{1}$ means that the coupling is antiferromagnetic (AF) coupling. From Eq. (2) it appears that changes periodically coupling of the AF coupling state to a FM coupling state. This causes oscillations in the GMR ratio against thickness of $\mathrm{CuO}$.

\subsubsection{Effect of $\mathrm{CoFe}_{2} \mathrm{O}_{4}$ layer thickness}

GMR ratio curve profile of the sandwich $\mathrm{CoFe}_{2} \mathrm{O}_{4} / \mathrm{CuO} / \mathrm{CoFe}_{2} \mathrm{O}_{4}$, is shown in Fig. 4. $\mathrm{CoFe}_{2} \mathrm{O}_{4}$ layer thickness affects the saturation field, $H_{s}$. Saturation field increases with increasing layer thickness ferrimagnetic, $\mathrm{CoFe}_{2} \mathrm{O}_{4}$. Increasing the saturation field is characterized by increasingly sharpening the peak of the curve GMR ratio. This is due to the more magnetic fraction of the atoms close neighbour in each layer $\mathrm{CoFe}_{2} \mathrm{O}_{4}$ when $\mathrm{CoFe}_{2} \mathrm{O}_{4}$ layer thickness increases.

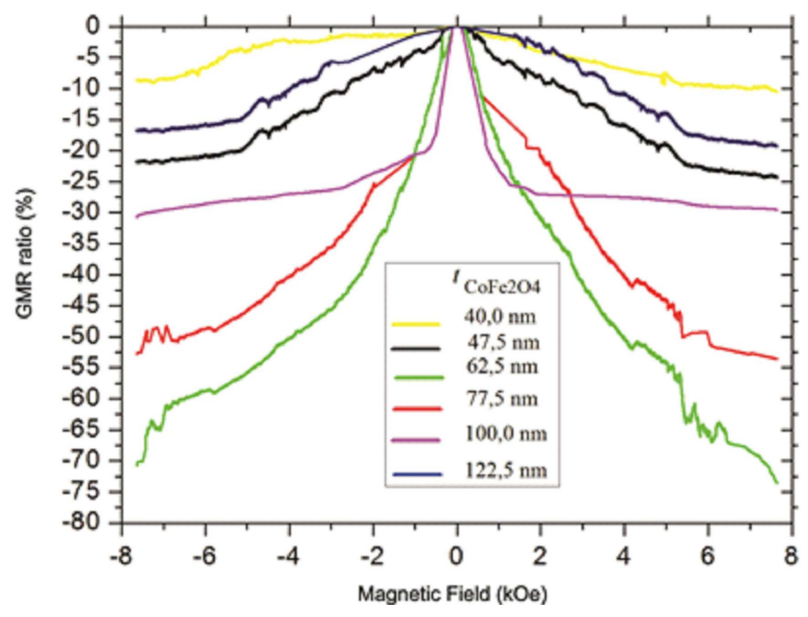

Fig. 4. GMR ratio curves of $\mathrm{CoFe}_{2} \mathrm{O}_{4} / \mathrm{CuO} / \mathrm{CoFe}_{2} \mathrm{O}_{4}$ with different $\mathrm{CoFe}_{2} \mathrm{O}_{4}$ layer thickness at fixed $\mathrm{CuO}$ layer thickness $14.4 \mathrm{~nm}$.

As shown in Fig. 4, the maximum value of the GMR ratio found in the $\mathrm{CoFe}_{2} \mathrm{O}_{4}$ layer thickness of $62.5 \mathrm{~nm}$. The maximum position is assumed to be related to the location of the center of the spin dependent scattering in a layer of ferro/ferri-magnetic [16]. The GMR ratio increased with increasing $\mathrm{CoFe}_{2} \mathrm{O}_{4}$ thickness, for thickness less than $62.5 \mathrm{~nm}$. However, when the $\mathrm{CoFe}_{2} \mathrm{O}_{4}$ layer thickness larger (greater than $62.5 \mathrm{~nm}$ ), the value of the GMR ratio decreases with increasing the $\mathrm{CoFe}_{2} \mathrm{O}_{4}$ thickness.

Explanation for this phenomenon, we propose appears an inactive part in the $\mathrm{CoFe}_{2} \mathrm{O}_{4}$ layer which shunt the current, and will reduce the GMR ratio. The $\mathrm{CoFe}_{2} \mathrm{O}_{4}$ layer can be divided into active and inactive region. Active part will give the main contribution to the GMR ratio while inactive part will shunt the current and reduce the GMR ratio. The above explanation refers to the work by Dieny et al. [16] when describing the phenomenological theory of GMR spin valve.

\section{2. $\mathrm{CoFe}_{2} \mathrm{O}_{4} / \mathrm{CuO} / \mathrm{CoFe}_{2} \mathrm{O}_{4} / \mathrm{FeMn}$ spin valve}

Growth of thin film of GMR spin valve structure has been done by varying the deposition time. Spin valve structure consists of sandwich structure that given a pinned antiferromagnetic layer of FeMn. The $\mathrm{CoFe}_{2} \mathrm{O}_{4}$ and $\mathrm{CuO}$ layer thickness were $47.5 \mathrm{~nm}$ and $14.4 \mathrm{~nm}$, respectively, while FeMn layer thickness are varied between $30 \mathrm{~nm}$ to $60 \mathrm{~nm}$.

The GMR ratio of a thin film of $\mathrm{CoFe}_{2} \mathrm{O}_{4} / \mathrm{CuO} / \mathrm{CoFe}_{2} \mathrm{O}_{4} / \mathrm{FeMn}$ spin valve as a function of FeMn layer thickness is shown in Fig. 5. The maximum GMR ratio of $32 \%$ was obtained on a sample with a FeMn layer thickness of $45 \mathrm{~nm}$. FeMn has a high resistive layer $(95 \mu \Omega \mathrm{cm})$ that is used to lock the magnetization in the ferrimagnetic layer through the exchange anisotropy. When the magnetic field is reversed (negative direction), the magnetoresistance effect does not occur, this is caused by the presence of layer of FeMn antiferromagnetic which only just passed one direction of magnetization.

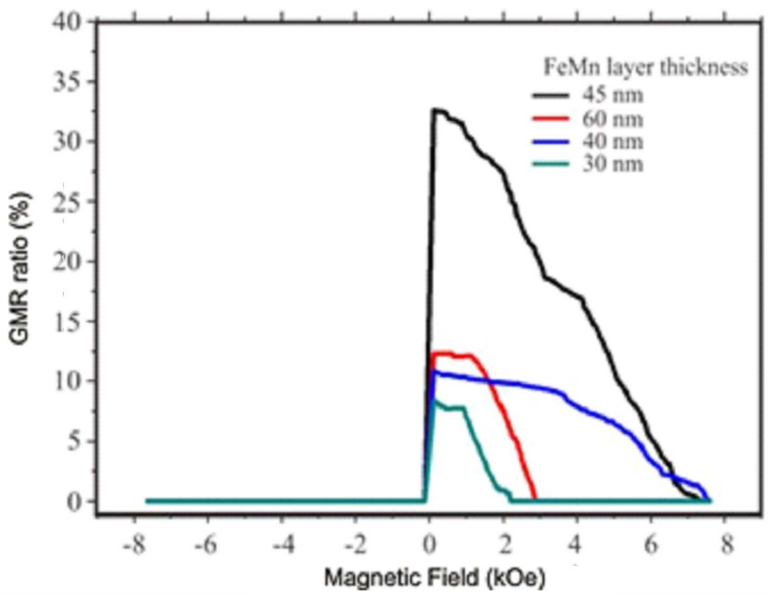

Fig. 5. The GMR ratio curves to the magnetic field of GMR spin valve $\mathrm{CoFe}_{2} \mathrm{O}_{4} / \mathrm{CuO} / \mathrm{CoFe}_{2} \mathrm{O}_{4} / \mathrm{FeMn}$ for various FeMn layer thicknesses.

\section{3. $\mathrm{CoFe}_{2} \mathrm{O}_{4} / \mathrm{Alq}_{3} / \mathrm{CoFe}_{2} \mathrm{O}_{4}$ organic $\mathrm{GMR}$}

More recently, research on GMR is directed to the use of organic materials as a spacer layer. To demonstrate the effect of the use of organic material as a spacer layer on GMR ratio thin film structured $\mathrm{CoFe}_{2} \mathrm{O}_{4} / \mathrm{Alq}_{3} / \mathrm{CoFe}_{2} \mathrm{O}_{4}$ was made. GMR ratio curves of GMR thin organic layer is shown in Fig. 6 for growth time 10, 15 and 20 minutes. It was found that the GMR ratio is: $10 \%, 35 \%$ and $12 \%$, respectively. The thickness of each layer for the growth time 10, 15 and 20 minutes are: $\mathrm{CoFe}_{2} \mathrm{O}_{4}(100 \mathrm{~nm}) / \mathrm{Alq}_{3}(48 \mathrm{~nm}) / \mathrm{CoFe}_{2} \mathrm{O}_{4}(100 \mathrm{~nm}) ;$ $\mathrm{CoFe}_{2} \mathrm{O}_{4}(137 \mathrm{~nm}) / \mathrm{Alq}_{3}(72 \mathrm{~nm}) / \mathrm{CoFe}_{2} \mathrm{O}_{4}(137 \mathrm{~nm}) ;$ $\mathrm{CoFe}_{2} \mathrm{O}_{4}(175 \mathrm{~nm}) / \mathrm{Alq}_{3}(96 \mathrm{~nm}) / \mathrm{CoFe}_{2} \mathrm{O}_{4}(175 \mathrm{~nm})$. The maximum value of GMR ratio $35 \%$ was obtained at room temperature for 15 minutes time of growth.

As shown in Fig. 6, the GMR ratio is not monotonically decreases with the thickness of each layer in 


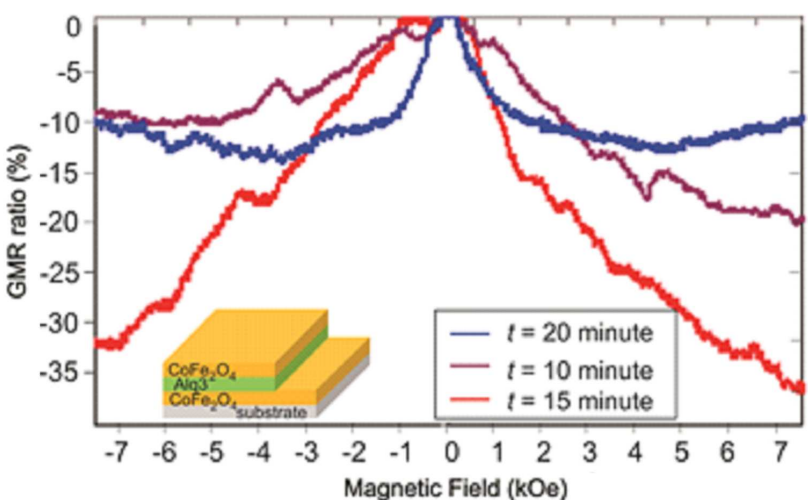

Fig. 6. The GMR ratio curve of $\mathrm{CoFe}_{2} \mathrm{O}_{4} / \mathrm{Alq}_{3} / \mathrm{CoFe}_{2} \mathrm{O}_{4}$ with varying time of growth.

$\mathrm{CoFe}_{2} \mathrm{O}_{4} / \mathrm{Alq}_{3} / \mathrm{CoFe}_{2} \mathrm{O}_{4}$ and spacer layer thickness. It can be caused by voltage variations are used in the process of growth. In this experiment, for the time of growth 10,15 and 20 minute average voltage supplied are; 78.4, 154.1 , and $95.2 \mathrm{mV}$, respectively. It seems that the different applied voltage in layers growing process accidentally enhances the GMR ratio, as it is used in electrical conditioning [16]. It has been found that with increasing the applied voltage, the GMR ratio also increased, as shown in Fig. 7.

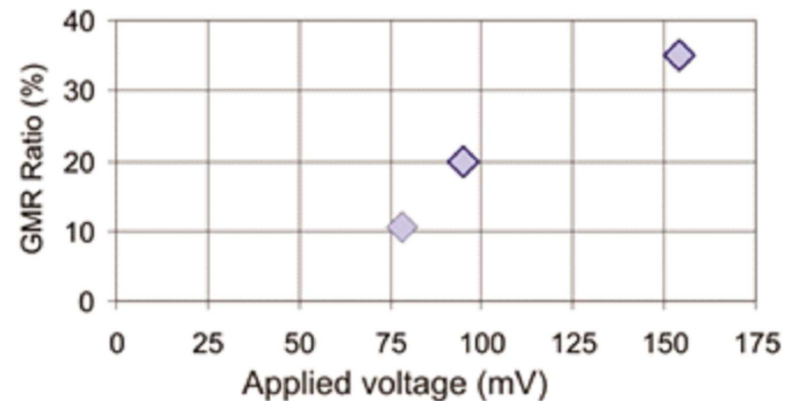

Fig. 7. Influence of voltage against the GMR ratio of $\mathrm{CoFe}_{2} \mathrm{O}_{4} / \mathrm{Alq}_{3} / \mathrm{CoFe}_{2} \mathrm{O}_{4}$.

\section{Summary}

Giant magnetoresistance (GMR) material based on cobalt ferrite $\left(\mathrm{CoFe}_{2} \mathrm{O}_{4}\right)$ have been successfully developed, namely the sandwich structure of $\mathrm{CoFe}_{2} \mathrm{O}_{4} / \mathrm{CuO} / \mathrm{CoFe}_{2} \mathrm{O}_{4}$, spin valve of $\mathrm{CoFe}_{2} \mathrm{O}_{4} / \mathrm{CuO} / \mathrm{CoFe}_{2} \mathrm{O}_{4} / \mathrm{FeMn}$, and organic GMR of $\mathrm{CoFe}_{2} \mathrm{O}_{4} / \mathrm{Alq}_{3} / \mathrm{CoFe}_{2} \mathrm{O}_{4}$. The growth parameters are growth temperature $100{ }^{\circ} \mathrm{C}$, argon gas flow rate of $100 \mathrm{sccm}$, deposition pressure 0.54 Torr, and the plasma voltage of 600 volts, while time of growth can be varied. In sandwich structure, the GMR ratio is influenced by $\mathrm{CuO}$ and $\mathrm{CoFe}_{2} \mathrm{O}_{4}$ layer thickness. The maximum value of GMR ratio obtained from the sandwich structure is $70 \%$ at $\mathrm{CoFe}_{2} \mathrm{O}_{4}$ and $\mathrm{CuO}$ layer thickness of $62.5 \mathrm{~nm}$ and $14.4 \mathrm{~nm}$, respectively. Meanwhile, the maximum GMR ratio of the spin valve structure and organic GMR are $32.5 \%$ and $35.5 \%$, respectively.

\section{References}

[1] M. Djamal, Ramli, F. Haryanto, Khairurrijal, GMR Biosensors for Clinical Diagnostics, in: Biosensors for Health, Environment and Biosecurity, Ed. P.A. Serra, InTech, Rijeka 2011, p. 149.

[2] B.G. Toth, L. Peter, L. Pogany, A. Revesz, I. Bakonyi, J. Electrochem. Soc. 161, D154 (2014).

[3] Ramli, E. Sustini, N. Rauf, M. Djamal, Adv. Mater. Res. 979, 85 (2014).

[4] Ramli, M. Djamal, F. Haryanto, S. Viridi, Khairurrijal, Adv. Mater. Res. 535, 1319 (2012).

[4] R.G.Mani, A. Kriisa, W. Wegscheider, Sci Rep. 3, 2747 (2013).

[5] J-W. Yoo, H.W. Jang, V.N. Prigodin, C. Kao, C.B. Eom, A.J. Eptein, Phys. Rev. B 80, 205207 (2009).

[6] J.H. Miao, S.L. Yuan, L. Yuan, G.M. Ren, X. Xiao, G.Q. Yu, Y.Q. Wang, S.Y. Yin, Mater. Res. Bull. 43, 631 (2008).

[7] H. Matsuda, H. Sakakima, J. Phys. D 44, 105001 (2011).

[8] N. Tezuka, J. Mag. Magn. Matter. 324, 3588 (2012).

[9] J.P. Moussy, J. Phys. D 46143001 (2013).

[10] B.D. Culity, C.D. Graham, Introduction to Magnetic Materials, John Wiley \& Sons, New Jersey 2009.

[11] J. Lee, J.Y. Park, Y. Oh, C.S. Kim, J. Appl. Phys. 84, 2801 (1998).

[12] C. Suryanarayana, M.G. Norton, X-ray Diffraction, A Practical Approach, Plenum Press, New York 1998.

[13] S. Zhang, P.M. Levy, J. Appl. Phys. 73, 5315 (1993).

[14] P. Bruno, C. Chappert, Phys. Rev. Lett. 67, 1602 (1991).

[15] B. Dieny, P. Humbert, V.S. Speriosu, S. Metin, B.A. Gurney, P. Baumgart, H. Lefakis, Phys. Rev. B 45, 806 (1992).

[16] U. Niedermeier, M. Vieth, R. Pätzold, W. Safert, H. von Seggern, Appl. Phys. Lett. 92, 193309 (2008). 